RESEARCH ARTICLE

\title{
The Terezita Romo Papers: Capturing the Spirit of Collective Action in Archives
}

\author{
Moriah Ulinskas \\ University of California, Santa Barbara and California State University, Sacramento, US \\ moriah.ulinskas@gmail.com
}

This article addresses the Terezita Romo Papers, one of a handful of archival collections of the Royal Chicano Air Force-a large collective of young, mostly immigrant or first-generation Mexican American artists and activists who produced countless community events and art projects and programs in Sacramento, California during the second half of the twentieth century. While membership of the Royal Chicano Air Force (RCAF) and its activities are hard to calculate, its history has been shaped by a tendency towards iconization of the group's male founders in archival description. Specifically, where collections are described to highlight the unique contributions of individuals, it is difficult to retain and promote the collective voice of action which made so many of these movements successful. Using the papers of Tere Romo, one member of the RCAF, this paper looks at how the archives of the RCAF have tended towards iconization-overshadowing the contributions of its female members-and explores ways in which archivists can reconsider the language of archives when processing and describing materials documenting collective action in American history.

Keywords: Archival description; Collective action; Chicana art; Chicano movement; Sacramento

\section{Introduction}

The second half of the twentieth century saw unprecedented swells of collective action as people's movements and grassroots organizations, comprised primarily of young idealist activists, formed to fill in where government had failed. In Sacramento, California, the most famous of these groups was the Royal Chicano Air Force-a large collective of young, mostly immigrant or first-generation Mexican American artists, university students and professors, and political activists who produced posters and community murals, a free breakfast program for children, arts programs in schools, Chicano sports tournaments, mental health services, and countless community events.

While the membership of the Royal Chicano Air Force (RCAF) is hard to calculate, its history has been shaped by a tendency towards iconization of a few individuals. Despite its foundation as a collaborative based on labor equity, the archives of the RCAF have tended towards masculine iconization, overshadowing the contributions of its female members. This essay asks: Where have archival practices failed to take the necessary steps to challenge the iconization, hegemony, and patriarchy which perpetuate inequalities in the historical record? How can archivists retain and promote the collective voice of action which made movements such as the RCAF so successful-especially within manuscripts archives, where collections are described to highlight the unique contributions of individuals? By analyzing existing RCAF finding aids in light of anti-chauvinist strategies developed in the field of Chicana studies, this essay seeks to identify some of the ways in which traditional archival description leads towards masculine iconization. Borrowing both from Chicana studies and recent archival studies, it also aspires to inform a new methodology for the description of a new RCAF collection: the Terezita Romo papers.

Through a graduate student fellowship at California State University, Sacramento, I was invited to work with the Special Collections and University Archives and enthusiastically took on the project of processing the Romo papers. Having spent over a decade in the San Francisco Bay Area arts scene, I was very familiar with 


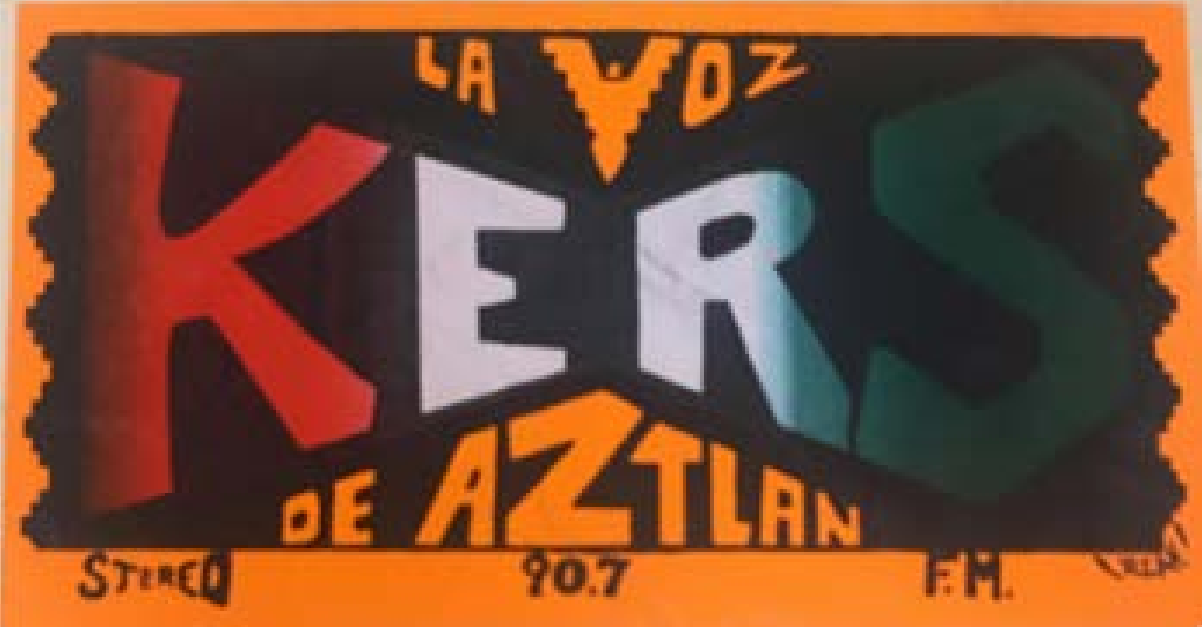

Figure 1: Bumper sticker from the Tere Romo papers, circa 1976. Romo submitted a proposal to KERS, CSUS's student-run radio station, to produce the station's first Spanish language program. From May $1-9$ of the same year, she organized the 'Chicano Marathon,' nine straight days of Spanish language and Latin music programming. The Romo collection contains letters and postcards thanking the station from people all across the state.

Tere's work as a curator and advocate for artists of color. While I was well aware of her influence as a program director and administrator, I knew little about her own artistic work and was genuinely surprised to learn about her role in the Royal Chicano Airforce, a well-known artists' collective from the 1970s. As I spent weeks sifting through funding proposals, event permits, and organizational by-laws and descriptions authored by Romo, it became clear to me that the labor of the RCAF women had become almost invisible in its history, and I became determined to use this as an opportunity to bring women like Romo to the foreground.

Terezita (Tere) Romo was born in Guadalajara, Mexico in 1952 and moved to Sacramento, California with her family at the age of three. She grew up in the Southside neighborhood of Sacramento, moving in her teens to Alkali Flat, a diverse community shaped by discriminatory housing covenants, which later became the epicenter of RCAF activities.' After completing an undergraduate degree in Psychology at Lone Mountain College in San Francisco, Romo returned to Sacramento to begin graduate studies in Social Work at California State University (CSUS). While at CSUS, she became an organizer for 'La Voz de Aztlán,' a weekly Spanish and English language music and educational program on the campus radio station, KERS, for which she organized the 'Chicano Marathon,' which featured a 24-hour, week-long Spanish language and Chicano program (see Figure 1).

Romo served as a mental health counselor at the Sacramento Concilio's a Orogram (see Figure 1).

(2) Finter (see Flo Health, which utilzed cultur and consions to Romo learned the power of arts and culture in mental health and community resilience.

At jon

'Develongent of Sacramento's downtown displaced many of the are's Latinos, the majority of whom relocated to the older Alkali Flats and Southside neighborhoods, which bookend downtown Sacramento on its north and south ends. Between 1950 and 1970, the Latino population nearly quadrupled, while the overall population of the area decreased by more than one-thirc. Homeownership in newly developing suburbs was racially restriced, leading to the development of densely populated minority

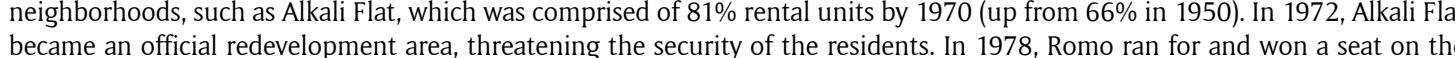
Alkali Flat Project Area Committee For more on this history see 'Chapter 3: Alkali Flat and the Chicano Movement' in William Burs Sacramento Renaissance: Art, Music \& Activism in California's Capital City (Mount Pleasant, SC: Arcadia Publishing, 2013). Solis was one of the founders of Instituto Familiar de la Raza, a mental health institution founded in San Francisco in the 1970s, which integrated Chicano/Latino concepts of familitia 'into culturally literate care. He also served as the clinical director of Concilio cited in foundational Chicano Studies publications. See Michael Soldatenko, Chicano Studies: The Genesis of a Discipline (Turson University of Arizona Press, 2013) and Latina/o Healing Practices: Mestizos and Indigenous Perspectives, edited by Brian McNeill and Jose M. Cervantes (New York: Taylor \& Francis, 2008). art gallery. Romo also worked on the Breakfast for Niños and Alkali Redevelopment Project Area Committee with other members of the RCAF and its allied organizations, and produced programs such as the Fiesta de Colores, Fiesta de Máz and Día de los Murtos through the collaborative Cultural Affairs Committee. Like other women in the RCAF, Romo aso played a leadeship role in the management and administration of the RCAF's many prograns and activites. Subsequenty, she worked at the Califonia Arts Council and

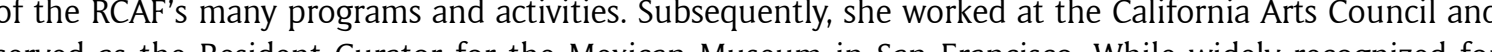
served as the Res to her contributions to the world of Latin Anerican and Indigenous Anercan contemporary art and locally recognized as a con ther is prominent in RCAF finding aids.

In 2009, Romo donated her personal archives to the Special Collections \& University Archives at California State University. Most of the other archival collections documenting the history of the RCAF had previously been acquired by the University of California Santa Barbara, as a part of the California Ethnic and

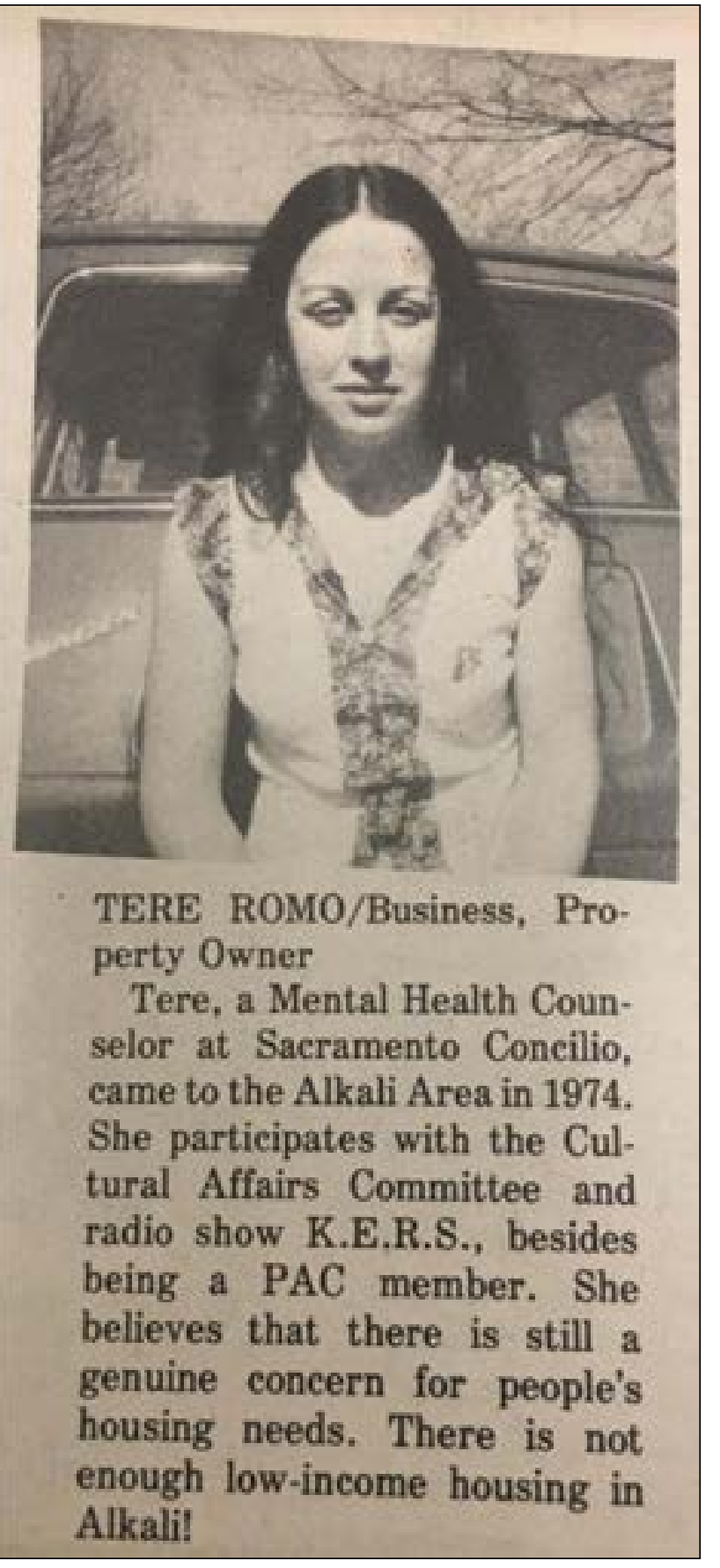

Figure 2: Loose newspaper clipping from the Tere Romo papers, n.d. 

Multicultural Archives (CEMA). Forever an egalitarian, Romo immediately recognized the limited ways in which is nould bor the collection is not 'about replacing one metanarrative with another, but smashing the notion that any community's past can bould

her work with the RCAF.

\section{The Problem of Provenance: Confronting Biases in Archival Description}

Provenance was established as, and still remains, the core of archival arrangement in the United States. According to Kathleen D. Roe's instructive text, Arranging \& Describing Archives \& Manuscripts (2008), the archivist should establish order in a collection by relying first on the principle of provenance, defined as the relationship between the record and the creator. However, this idea assumes that both authorship an ownership are individual activities expressed through individual creators, such as in a collection of persona papers' (Bastian 2003). Traditional standards such as provenance and respect des fonds prescribe that records cannot be intermingled with those of other creators. So how can archivists organize records that resulted from collective action even if they arrived at the archives through individual donations?

Abolitionist archivist Jarrett Drake (2016) writes in 'RadTech Meets RadArch: Towards A New Principle for Archives and Archival Description' that 'I have come to understand that provenance, which is perhap the most sacred principle in the archival field and the principle that most shapes archival description in the United States, is at once a relic of the colonial and imperial era in which it emerged.' If archives are to provide evidence of actions and events, to preserve both individual and collective memory, then archives professionals must find a way to move beyond the inherent bias present in current practices of records creation and archival description. Standards in archival description favor the notion of single records creators and provide limited options for describing records that can represent a multiplicity of voices.

The archivist's work is central to the shaping of history, as archivists not only choose which records to preserve (and which not to preserve) but also how to frame the narrative of those retained records. Over the last century, Drake (2016) observes, the patriarchal origins of provenance penetrated the language of archival description,' lending towards the perpetuation of 'great man history'-even in unexpected places such as the RCAF archives. Drake points out that finding aids, specifically biographical notes, function as 'massive memorials' which 'have minimal bearing on the records, and instead valorize and venerate white western masculinity.' He recommends that the repetitive use of adjectives like 'distinguished,' 'significant, 'prestigious,' and 'prominent' in finding aids, which elevate some individuals in the historical record, should be analyzed alongside the long silences and deep chasms where other voices should, but do not, appear en of history, what does this .

There is a long-held misconception that archivists are objective custodians of historical records, and that archival records have a natural order to them which the archivist's job is to describe and maintain. However 'the archival record doesn't just happen,' writes Elisabeth Kaplan in 'We Are What We Collect' (2000): 'It is created by individuals and organizations, and used, in turn, to support their values and mission, all of which compromises a process that is certainly not politically and culturally neutral.' The assumed natural order of records in archives has tended towards the perpetuation of inequalities by advancing the historical narratives of the dominant and maintaining the silence of the disenfranchised. Archivists today are working to create new systems to confront the biased structures inherent in archival description.

\section{Righting/Writing the Record: Amplifying Women's Voices through}

\section{Archival Description}

There are currently six collections findable through the Online Archive of California which contain primary records of the RCAF. They are: the Esteban Villa Papers, the José Montoya Papers, the Luis C. González Papers, the Royal Chicano Air Force Poster Collection, the Ricardo Favela Royal Chicano Air Force Poster Collection, and the Royal Chicano Air Force Archives. Their titles alone suggest that four of these six collections are filtered through the experience and authority of individual men who were founding members of the group. While the collected papers of Villa, Montoya, and González pertain to their lives both within and outside of the RCAF, the collections share the same biographical text, which emphasizes the founding legacy of the RCAF: The founding members of the RCAF include José Montoya, Esteban Villa, Juanishi V. Orosco, Ricardo Mexican American Liberation Art Front and the California College of Arts and Crafts. During the Mexicano American Liberation Art Front and the California College of Arts and Crafts. During the Chicano Movement students pressured colleges and universities to diversify their faculties. As a result,
Montoya and Villa were hired as professors of art at California State University, Sacramento. Their Montoya and Villa were hired as professors of art at California State University, Sacramento. Their academic positions gave them the creative freedom to initiate programmatic exchanges between theu-
niversity and the barrio community.

This is the only time that members of the RCAF are named in the finding aids and, despite the group's growth into a large collective of both men and women, this early definition of the group fixes its description as a male-dominated organization. This narrative lays the foundation for the rest of the finding aids' text, which continue to valorize a few men, and perpetuates their iconization while ignoring the group's later expansion into a large, multifaceted collective. The biographical note goes on to state that

The RCAF created in 1972 the not-for-profit Centro de Artistas Chicanos. This community based organization became the spring-board for all types of Sacramento community programs, such as La Nueva Raza Bookstore (with its Galería Posada), Aeronaves de Aztlán (Automotive Repair Garage), RCAF Danzantes (Cultural Dance venue), Barrio Art Program, and the RCAF Graphics and Design Center. By 1977, the Centro de Artistas Chicanos and Breakfast for Niños Program (a community non-profit program that fed children before school) joined forces to create the Cultural Affairs Project, which further funded their many community services.

At no point in the finding aid does the archival description expand on who came to comprise the RCAF or organize its activities, perpetuating the false notion that it was this group of men who alone produced these many projects and programs. Furthermore, while RCAF members describe the programs and events as a critical components of the collective's art practice, it is the visual work that has garnered the most attention in RCAF's lasting legacy. This misrepresentation is perpetuated by the narrative of the RCAF finding aid(s):

The $R C A F$ is best known for its mural paintings, poster art production, and individual artistic contribu-
tions. The artists of the Centro have produced murals and exhibitions from San Diego to Seattle. RCAF tions. The artists of the Centro have produced murals and exhibitions from San Diego to Seattle. RCAF is significant as a collective that has maintained a twenty-five year history of engaging communities to express their Chicano culture, history and struggle for equal rights. Ella Maria Día's history of the RCAF, Flying Under the Radar with the Royal Chicano Air Force: Mapping a RCAF ma Art History (2017), uses in-person interviews, artifacts, and evidence from archives containing RCAF materials to uncover the eclipsed history of women of the RCAF. Diaz dedicates an entire chapter to 'puscussion of the ways in which CConder and to 'put forward a fraternal vision of decorization' both Diaz's book and the content establishment and and the Galeria Posala and speast the many annians permits, contracts, grant proposals, and correspondence, most of which were authored by the women of RCAF. Meet 5 nos and $\mathbf{5}$ ). Yet it is the men and the graphic posters, the bulk of which were made to promote abovementioned activities, which receive the most attention in the group's historical legacy.

'Many RCAF artists find the absence of Chicanas in analyses and exhibitions of their artwork problematic,' writes Díaz, 'because it misrepresents the collective's artistic philosophy, which centered on labor equality and collaboration' (2017: 123). The same is true in tracing the history of similar Chicana/o arts collectives of the time, including, but not limited to, Pattsi Valdez of Asco and Kathy Vargas of Con Safo. ${ }^{3}$ Yet little has been done to correct the historical record, especially as it is described and discoverable in archives. Díaz

See Chon Noriega, 'Your Art Disgusts Me,' Afterall: A Journal of Art, Context and Enquiry, (Autumn/Winter 2008): 109-21 and Ruben Cordova, , On Safo: The Chicano Art Group and the Politics of South Texas (Oakland, CA: UCLA Chicano Studies Research
Center, 2011). 


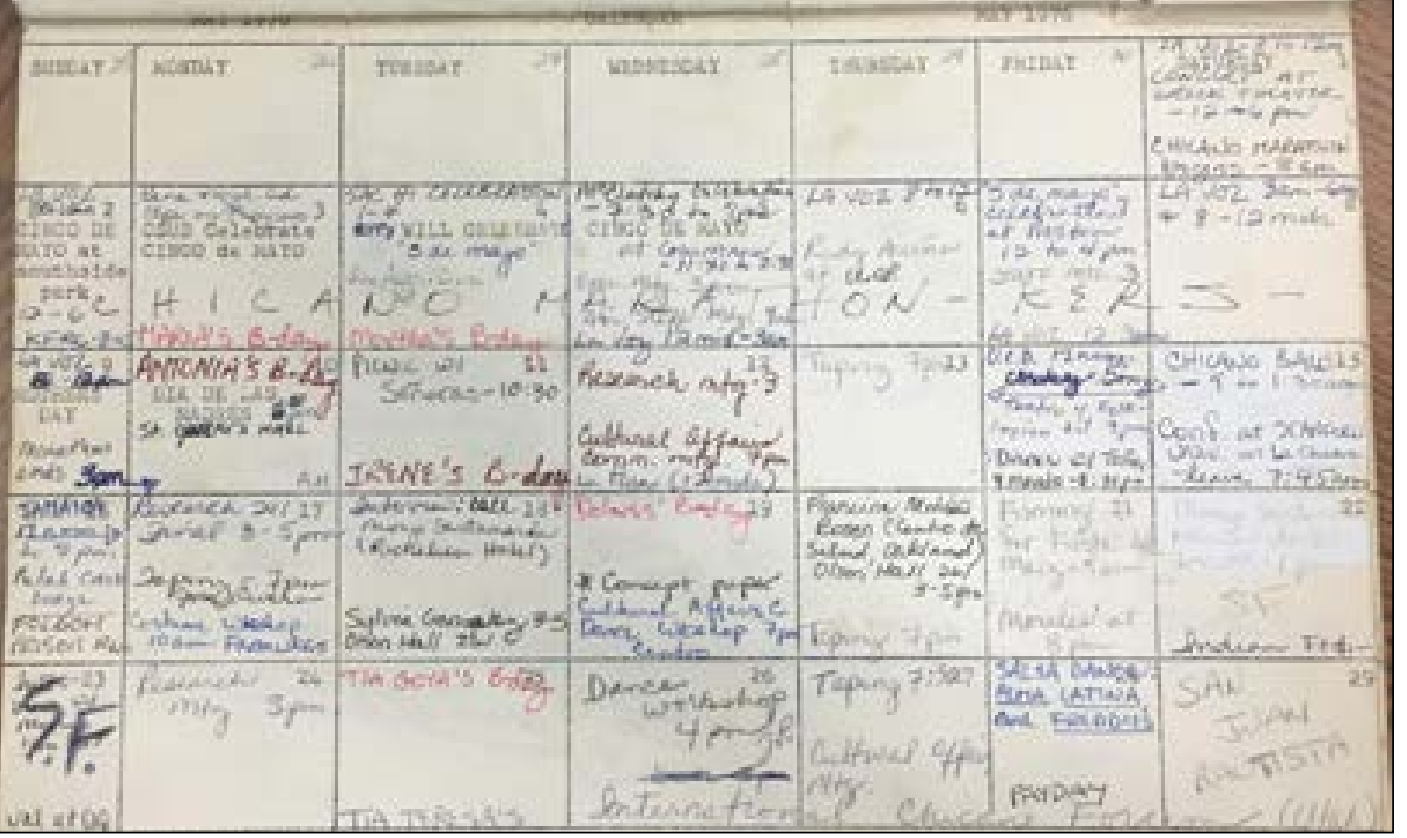

Figure 3: Tere's calendar, May 1976. This one-month snapshot captures the intensity of programming Tere and the RCAF produced. It includes the Chicano Marathon, Cinco de Mayo celebrations at Soutside Park events, and academic conferences and research sessions. Romo's collection contains her calendars and planners from 1975-2002.

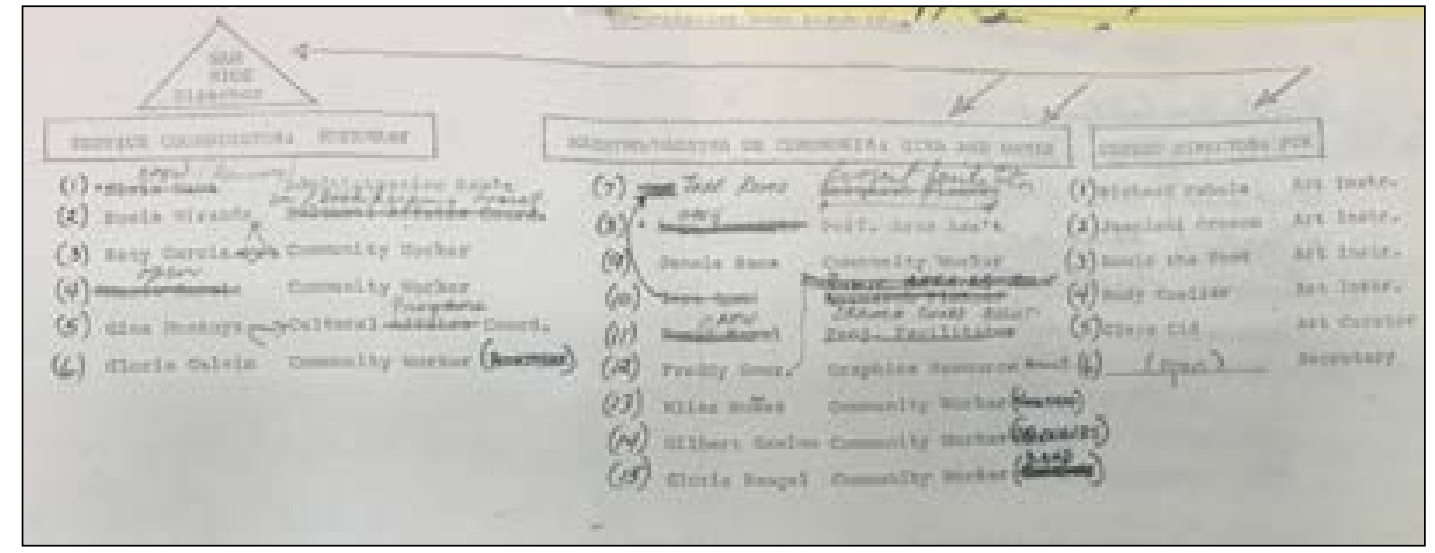

Figure 4: Cooperative Work Structure, Cultural Affairs Committee, 1970s. This document from the Rom collection clearly demonstrates the primary role women played in the collaborative activities of RCAF. In this detailed diagram of the collective work structure, the first ten members named (with the exception of Sam Rios who was the CSUS faculty supervisor) are all women.

points out in her book that 'in order to hear [the women's] stories, the RCAF's records must be studied differently' (2017: 88). What we count as artwork must be expanded on to include all RCAF activities, not just the visual aspects. In retrospect, the activities of the RCAF are easily recognizable as a precursor to contemporary art practices often labeled 'community-based' or 'social-practice' oriented. Activities such as the free breakfast program (see Figure 6) were central to the RCAF's artistic practice, but the murals and posters were more easily and readily recognized as art, as well as more clearly documented and archivable. Those murals and posters, and their authors, reign supreme in the archives-and thus in the official history of the group. 'Turning up the volume on Chicana voices in RCAF history,' Díaz writes, 'means examining visual and performance art alongside meeting minutes, grant applications, interviews, and photographs' (2017: 89). The RCAF finding aids can and should be updated to either amplify and name the women of the collective or diminish the iconization of the small handful of men who have garnered a disproportionate amount of attention in the description of RCAF activities.

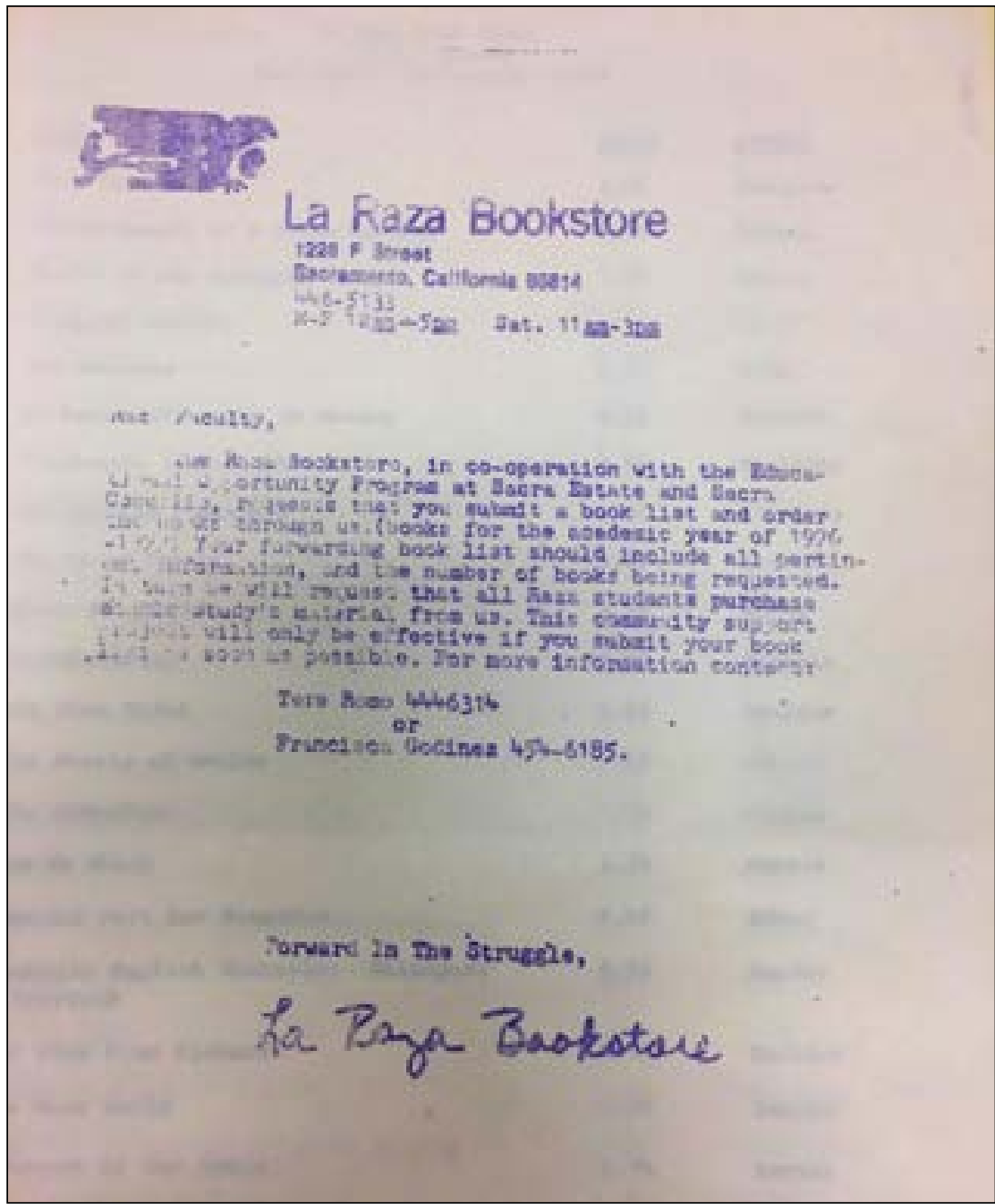

Figure 5: Letter requesting book recommendations for La Raza Bookstore, 1976. The bookstore was Figure 5: Letter requesting book recommendations for La Raza Bookstore, 1976. The bookstore was
established in 1972 by CSUS students as a resource for Latino and Chicano literature, which they found Jr. (who would later go on to become Sacramento's first Latino mayor), the bookstore was established as a cultural and political meeting place serving the area's Chicano community.

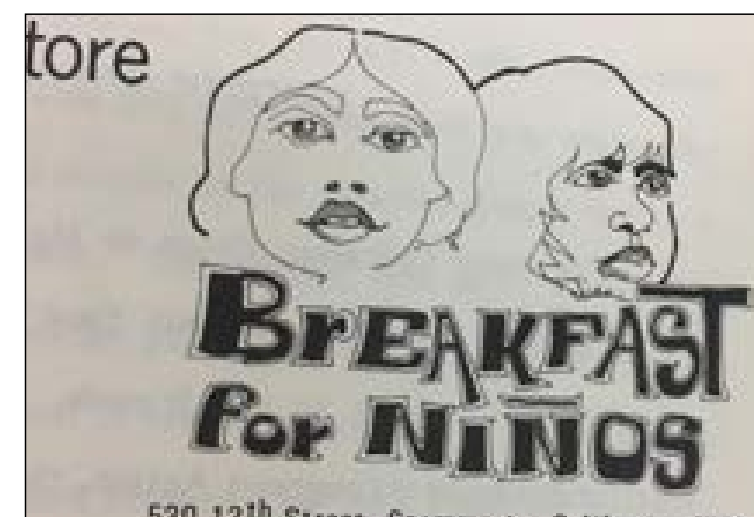

$53012^{\text {th }}$ Street Sacramente California 95814 Phone 446-6111

Figure 6: Breakfast for Niños logo, 1970s. One of RCAF's most significant community programs was Breakfast for Niños, which was modeled on the Black Panther Party's Free Breakfast program in the nearby African American community of Oak Park. Established by RCAF members Irma Lerma Berbosa and Lorraine GarcíaNakata, Breakfast for Niños became the fiscal and organizational umbrella under which much of RCAF's programming and funding was made possible. 


\section{Pitfalls of Positivism: Describing the Context of Records}

In 'Many Paths to Partial Truths: Archives, Anthropology, and the Power of Representation' (2002), Elisabeth Kaplan suggests that while most other fields in the humanities have been swept up in the postmodernist

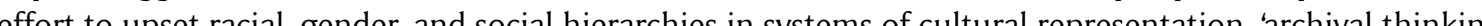
has remained largely isolated from this broader intellectual londscape, and archival practice has renained curiously bound up in modes of thought and practice distinctly rooted in 19th century posivis' curiously bound up in modes of thought and practice distinctly rooted in the century positivism (2002: 20). To recis recommend that archivists shift their focus from describing the content of collections to describing the context in which they were produced. 'Adequately documenting the provenance of records requires more than simply identifying the office of their creation," writes Deodato (2006), 'but also their social and cultura context and custodial history' (54). In breaking with archival standards, archivists are encouraged to think forward to how researchers will experience archival records and provide the context necessary so that biases and inequities which are recognizable in the production of records are not made invisible by the archivist's description and arrangement. Additionally, researchers should understand that archives are not neutra records, but problematic representations shaped by records collectors, archivists, and the researchers themselves. 'Archivization produces as much as it records the event,' writes Eric Ketelaar (2002): 'What has been excluded from the record determines its meaning as much as what was included. They both are part of the provenance' (223).

In the case of the RCAF archives, women of the Chicano movement have been eclipsed in the historical records by the activities and iconization of their male counterparts. Elisabeth Kaplan (2002) suggests that archivists can draw meaningful comparisons by drawing outside their field in disciplines, such a anthropology, with which archives shares key features, such as concern with issues of representation, description, and culture' (209). Strategies developed in Chicana studies, which both identify chauvinism within the historical record and work to illuminate the achievements of women within the movement, offer an important model for a more inclusive archival practice.

\section{Learning from Chicana Power and Feminist Ethics}

In Maylei Blackwell's iChicana Power!: Contested Histories of Feminism in the Chicano Movement (2015) Blackwell puts forward the proposal for what she calls 'retrofitted memory,' a form of counter memory that uses fragments of older histories that have been disjunctured by colonial practices of organizing historical knowledge or by masculinist renderings of history that disappear women's political involvement' (2). Retrofitted memory assumes that Chicano historiography generally denies women their place in $e$ Movimiento, and seeks to illuminate the silences in the historical record and populate these silences with Chicana women's stories. Ella Maria Díaz (2017), too, points out that 'once scholars have made the point that "el Movimiento was deeply saria" Diaz (2017), too, points out that 'once scholars have made the point that "el Movimiento was deeply sexist" what should they do next? I answer that they should remix the records, (isteric provide examples of how academic

Michelle Caswell and Maik Cifor (2016) make a radical suggestion for addressing chauvinism within Mich

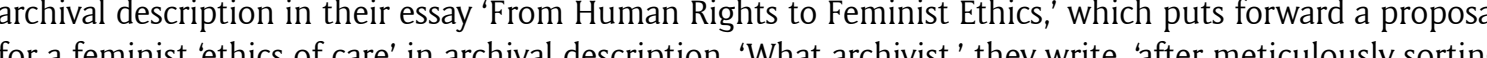
through through pages of dianies, folders of correspondence, and boxes of ephera, has not felt emotionally connected to the creator of a collection? (2016. 33-34) Caswell and Cifor outline a feminist approach to archival processing and description that acknowledges an emotional bond between the records creator and archivist and depends on that bond for the record description. They infer that the archivist enter into a relationship of care' with the records creator -whether the archivist has any point of contact with that person or not-which can seek to transform power inequities in archival description. Caswell and Cifor point out that, in order to enter a relationship of care, the archivist must develop a level of empathy for all parties involved in the creation of records, even those 'who held and exploited positions of power' (2016: 33-34). While this can be difficult to visualize in practice, what is important here is the exercise in self-reflexivity on the part of the archivist. The archivist's task of arranging and describing collections does more than articulate the natural meaning of records; it actively supports the construction of that meaning. Recognizing the archivist as a subjective author while maintaining empathy for the record creator allows researchers and others who come into contact with the records to better understand the content of a collection based on an understanding of the context in which it was produced, arranged, and described.
Traditional descriptive standards not only reduce some of the subjects or records producers to silence. They also erase the archivists themselves, suggesting a passive or objective voice in archival arrangement and description. As Jenifer Doughs states in 'Towards More Honest Description' (2016). "Is]ome of the and desciption. As Jennifer Douglas states in 'Towas convention effacen fint most finding aids, Douglas points out, is the passive voice, which wongly implies that the author is neutral (2016: 40). What can archivists do to rencdy these issues and bing he act of archival description into the twenty-fist century? How can I (as an archivist) produce a finding aid for the Terezita Romo papers that does not repeat the saye Hex archival recod? Taking lessons from Chicana of corporations and practices in community archiving, leads me to the following proposal.

\section{Disrespecting des Fonds: Towards a Methodology for Describing}

\section{Collective Action}

Respect des fonds, ${ }^{\prime 4}$ digital archivist Jefferson Bailey (2013) writes, 'was born of a particular historical moment, for a particular type of archival document, and was conceived of to address the practical needs of specific social circumstances.' Even as respect des fonds has evolved over time, he points out, it is still based on the central concept of records originating from a single records producer. In the instance of the Terezita Romo papers, much of which document Romo's significant contribution to the collective efforts of the RCAF, how can I, the archivist, describe these records in a way that recognizes both Romo's labor and the collective action that made RCAF activities possible? What opportunities exist, other than referencing related collections, to describe Romo's papers in a way that speaks to the collective nature of her work with the RCAF?

In his essay 'Becoming Responsible Mediators: The Application of Postmodern Perspectives to Archival Arrangement \& Description' (2006), Joseph Deodato states that 'modern records are often created, accumulated, and used by a variety of agencies and series of records frequently change custody from one organization to another. This makes the "one collection, one creator" idea of the record group untenable and necessitates an expansion of the conventional conception of provenance' (55). Deodato accuses archivists of presenting simplified, monolithic representations of what are really complex histories of authorship and ownership, and challenges them to develop methods of arrangement and description that recognize the limitations of traditional archival description. In his essay, Deodato quotes historian Tom Nesmith (2002), who observes in 'Seeing Archives: Postmodernism and the Changing Intellectual Place of Archives' that a record is a meaningful communication, which means it is a physical object, plus an understanding or representation of that object' (32). What both Deodato and Nesmith are driving at is than understanding or

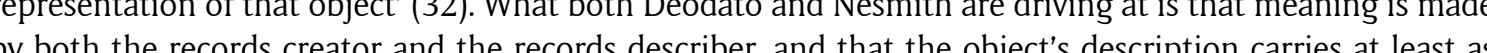
much importance as the object itself.

One of the most useful examples I have found, in the breaking away from traditional respect des fonds, is in the series versus fonds argument articulated in 'Stories and Names: Archival Description as Narrating Records and Constructing Meanings' (2002) by Wendy Duff and Verne Harris. In this essay, Duff and Harris weigh arguments made by different archivists who approach the challenge of describing the multifaceted origins of records. They outline a system, developed by the National Archives of Australia, to make the series the primary level of description. In this scenario, the original order is maintained within a collection, but the content is linked through description of the records to records in other collections at a series level, and contextualized by describing the relationship between the multiple records creators. '[T]he series system is based on the notion that records are multi-provenancial in nature,' they write, 'and that "creation is only one aspect of provenance"' (2002: 269). They argue that this system describes provenance, which 'includes the office that generated it as well as the agencies that subsequently added to it, controlled it, used it, even had mere custody of it' (Duff and Harris 2002: 271). In this system, the contribution of each records creator, as well as records describer or user, is added to the provenance. This detail changes the context of the record. It also allows a series to have multiple creators and thus be contained in multiple collections.

Respect des fonds, or le respect pour les fonds, is a principle in archival theory that proposes to group collections of archival records according to their fonds-that is to say, according to the administration, organization, individual, or entity by which they were
created or from which they were received. See Michel Duchein, 'Theoretical Principles and Practical Problems of Respect des Fonds in Archival Science,' Archivaria 16 (Summer 1983): 64-82. 

Another radical recommendation made by Duff and Harris includes a major intervention in the traditional framework of the finding aid, one which would allow records creators, archivists, and researchers all to annotate the finding aid. 'We need to create holes that allow in the voices of our users,' they write: 'We need descriptive architectures that allow our users to speak to and in then' (2002: 279). In this scenario, users of finding aids would have a place to add their own comments and insights into the records, as well as their relationships with others-something that is often discovered by researchers long after the finding aid has been completed. This proposal lends to the last trend in archival theory that I have used in the development of the Terezita Romo finding aid. participatory practices in arrangement and description. While it is not unusual for archivists to interview records creators during the appraisal period-nor is unusual for archivists to communicate with them for clarification while working on archival descriptionrecords creators are often relegated to being subjects once the collection has passed out of their ownership. Shilton and Srinivasan (2007) propose a process of dialogue that allows the records creator to edit and annotate the archival record, and 'move beyond objectification and aid understanding of local knowledge and marginalized narratives' (91)

In creating a finding aid for the Terezita Romo papers, what I have attempted is this: to develop the processing plan through dialogue, not only with professionals in the archive that has acquired the collection, but with Romo herself (see Figure 7). Romo's collection is comprised of three series, which capture 1) her early years as a student activist and mental health counselor, 2) her decades-long engagement with the RCAF, and 3) her individual career as an arts administrator, curator, and scholar. Within the collection, Romo's work with the RCAF is contained to a series titled 'Collaborative RCAF: 1974-2005,' which we hope to link, by description, to similar series in other RCAF members' archival collections. I am working closely with Romo to edit and annotate the finding aid as the description is developed, and I hope to invite other members of the RCAF to provide feedback on the descriptions of RCAF records that are captured in various collections. While the folders contained in this collection are restricted to the RCAF activities that Romo participated in, the series description describes the group in the following way:

This series contains records pertaining to the community activities and programs produced under the aegis of the Royal Chicano Air Force, of which Romo was a member. The Royal Chicano Air Force was a large collective of young, mostly immigrant or first generation Mexican American artists, university students and professors, writers, musicians, dancers and political activists who produced posters and

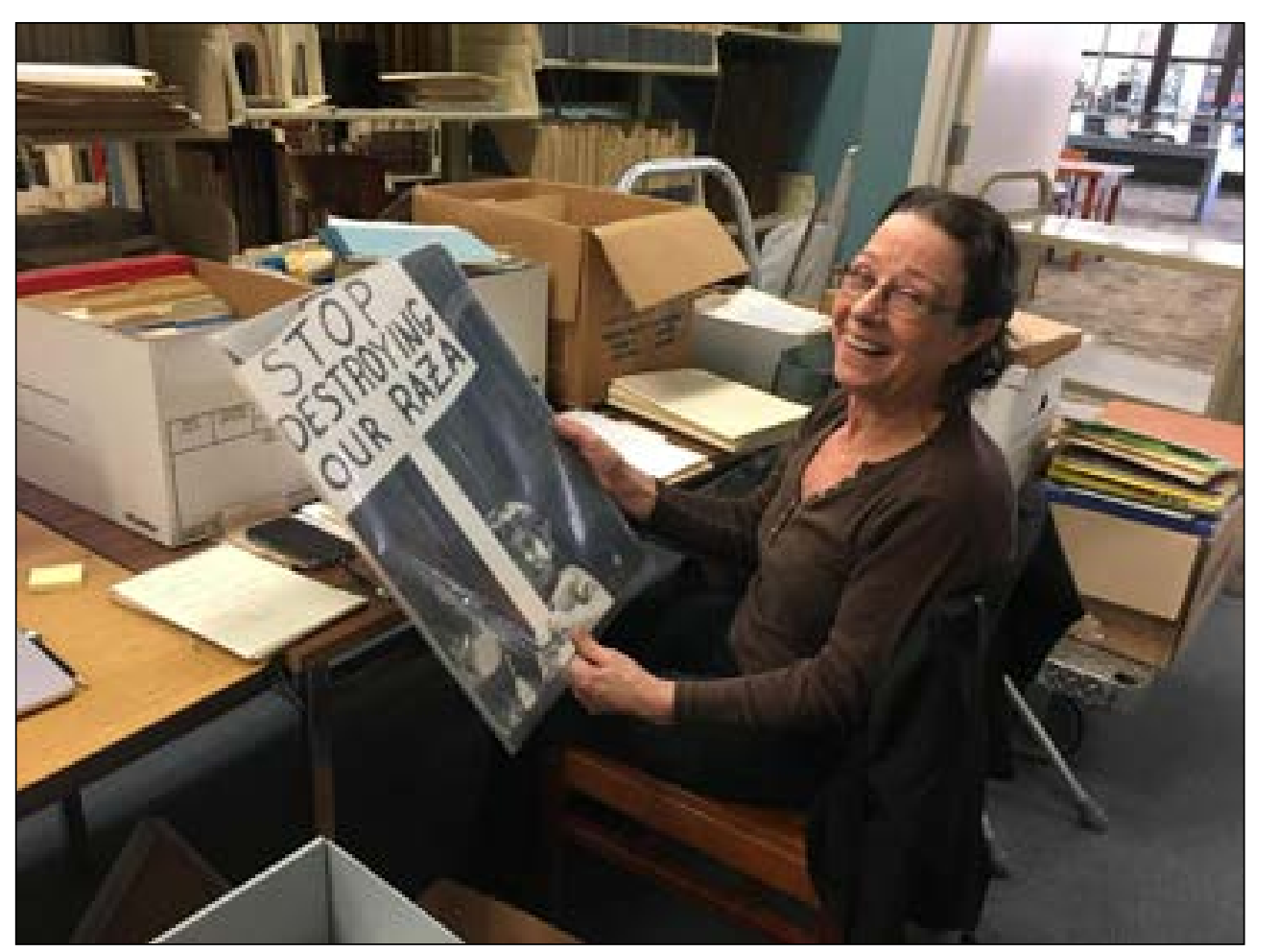

Figure 7: Tere Romo organizing her papers at SCUA, CSU, Sacramento. February 2018. Photograph by the author. community murals, a free breakfast program for children, arts programs in schools, Chicano sports Rebel Chicano Art Front the RCAF was founded in 1969 to express the goals of the Chicano civil rights and labor organizing movement of the United Farm Workers. Its mission was to make available to the

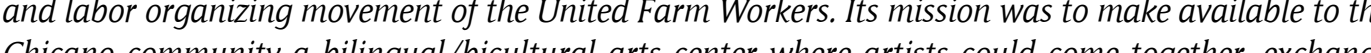
Chicano community a bilingual/bicultural arts center where artists could come together, exchange ideas, provide mutual support, and make available to the public artistic, cultural, and educational
programs and events.

In 'Colophons and Annotations: New Directions for the Finding Aid' (2002), Michelle Light and Tom Hyry suggest that archivists include colophons, or statements addressing the creation of a collection and its finding aid, in their work. In a colophon, the archivist can document their approach to the organization and description of the collection, as well as their decision-making process. Through this article, I have outlined the project of reclaiming a collective identity in the RCAF records, even as they exist in an individual collection. This essay will now serve as a colophon for the Tere Romo papers.

The new biographical sketch for RCAF collections can maintain the founding story of the collective while expanding outward to better describe the growth of the group over the years-by naming many of the individuals who led and participated in RCAF's projects and programs and linking series containing RCAF materials to each other. The RCAF was a collective based on labor equity. In reviewing the documents in the Romo collection, it became very clear to me how important it was for members to denounce any form of hierarchy within their group. Even while documenting the unique contributions of individuals, it is especially important for archivists organizing and describing their records to do so in a way that recognizes this and retains the collective nature of their history-especially, but not only, when those groups' values recognize the collaborative nature of records creation and human experience.

\section{Competing Interests}

The author has no competing interests to declare.

\section{References}

Bailey, Jefferson. 2013. "Disrespect des Fonds: Rethinking Arrangement and Description in Born-Digital Archives." Archive Journal. June. http://www.archivejournal.net/essays/disrespect-des-fonds-rethinkingarrangement-and-description-in-born-digital-archives/.

Bastian, Jeannette Allis. 2003. "In a 'House of Memory': Discovering the Provenance of Place." Archival Issues, 28(1): 9-19.

Blackwell Maylei. 2015. iChicana Power!: Contested Histories of Feminism in the Chicano Movement. Austin: University of Texas Press.

Caswell, Michelle. 2016 "Toward Survivor-Centered Approach to Human Rights Archives: Lessons from Community-Based Archives." UCLA. https://escholarship.org/uc/item/73f5s7sr.

Caswell, Michelle, and Marika Cifor. 2016. "From Human Rights to Feminist Ethics: Radical Empathy in the Archives." Archivaria, 81: 23-43. Spring. https://archivaria.ca/archivar/index.php/archivaria/article/ Archives." Archic

Deodato, Joseph. 2006. "Becoming Responsible Mediators: The Application of Postmodern Perspectives to Archival Arrangement \& Description." Progressive Librarian, 27: 52-63. Summer. http://www. to Archival Arrangement $\&$ Description." Progress
progressivelibrariansguild.org/PL/PL27/052.pdf.

Díaz, Ella Maria. 2017. Flying Under the Radar with the Royal Chicano Air Force: Mapping a Chicano/a Art History. Austin: University of Texas Press.

Douglas, Jennifer. 2016. "Toward More Honest Description." The American Archivist, 79(1): 26-55. DOI: https://doi.org/10.17723/0360-9081.79.1.26

Drake, Jarrett M. 2016. "RadTech Meets RadArch: Towards A New Principle for Archives and Archival Description." Medium, April 6. Accessed November 1, 2017. https://medium.com/on-archivy/radtechmeets-radarch-towards-a-new-principle-for-archives-and-archival-description-568f133e4325. Archived at: https://perma.cc/3UEA-7FV

Duff, Wendy M., and Verne Harris. 2002. "Stories and Names: Archival Description as Narrating Records and Constructing Meanings." Archival Science, 2(3-4): 263-85. DOI: https://doi.org/10.1007/bf02435625

This is the proposed revision of a standard $\mathrm{R}$.
archives holding RCAF collections to adopt. 
Kaplan, Elisabeth. 2000. "We Are What We Collect, We Collect What We Are: Archives and the Construction of Identity." The American Archivist, 63(1): 126-51. DOI: https://doi.org/10.17723/ aarc.63.1.h554377531233105

Kaplan, Elisabeth. 2002. "Many Paths to Partial Truths': Archives, Anthropology, and the Power of Representation." Archival Science, 2(3-4): 209-20. DOI: https://doi.org/10.1007/BF02435622

Ketelaar, Eric. 2002. "Archival Temples, Archival Prisons: Modes of Power and Protection." Archival Science 2(3-4): 221-38. DOI: https://doi.org/10.1007/BF02435623.

Light, Michelle, and Tom Hyry. 2002. "Colophons and Annotations: New Directions for the Finding Aid." The American Archivist, 65(2): 216-30. DOI: https://doi.org/10.17723/aarc.65.2.13h27j5x8716586q.

Nesmith, Tom. 2002. "Seeing Archives: Postmodernism and the Changing Intellectual Place of Archives." The American Archivist, 65(1): 24-41. DOI: https://doi.org/10.17723/aarc.65.1.rr48450509r0712u

Roe, Kathleen. 2008. Arranging \& Describing Archives \& Manuscripts. Chicago: Society of American Archivists.

Royal Chicano Air Force Archives. 2006. Finding aid at the Department of Special Collections, University Libraries, University of California, Santa Barbara. http://oac.cdlib.org/findaid/ark:/13030/kt9d5nd53d/.

Shilton, Katie, and Ramesh Srinivasan. 2007. "Participatory Appraisal and Arrangement for Multicultural Archival Collections." Archivaria, 63: 87-101. Spring. https://archivaria.ca/index.php/archivaria/article/ view/13129.

How to cite this article: Ulinskas, Moriah. 2018. The Terezita Romo Papers: Capturing the Spirit of Collective Action in Archives. KULA: knowledge creation, dissemination, and preservation studies 2(1): 4. DOI: https://doi. org/10.5334/kula.22

Submitted: 19 February 2018 Accepted: 16 August 2018 Published: 29 November 2018

Copyright: ๑ 2018 The Author(s). This is an open-access article distributed under the terms of the Creative Commons Attribution 4.0 International License (CC-BY 4.0), which permits unrestricted use, distribution, and reproduction in any medium, provided the original author and source are credited. See http://creativecommons.org/ licenses/by/4.0/.

$\mathrm{Ju}[$ KULA: Knowledge creation, dissemination, and preservation studies is a peer-reviewed

$|\mathrm{u}|$ open access journal published by Ubiquity Press. 